BRIEF REPORT

\title{
"Pack year" smoking histories: what about patients who use loose tobacco?
}

\section{M Wood, M G Mould, S B Y Ong, E H Baker}

Tobacco Control 2005;14:141-142. doi: 10.1136/tc.2004.009977

Life time smoking of ready made cigarettes can be readily quantified as "pack years" smoked, but methods for measuring loose tobacco use are less well established. In this study the frequency of loose tobacco use by 247 hospital in-patients was determined; $64 \%$ were current or ex-smokers, $41.3 \%$ of whom (25.9\% of participants) had smoked loose tobacco. A formula was developed for converting loose tobacco use to pack years smoked, based on the weight of tobacco in ready made cigarettes; $12.5 \mathrm{~g}$ or half an ounce of loose tobacco was approximately equivalent to one packet of 20 cigarettes. Using a questionnaire it was found that hospital physicians of all grades were able to convert smoking histories of ready made cigarettes, but not loose tobacco, into number of "pack years" smoked.

ifetime smoking exposure is quantified in "pack years", where one "pack year" is 20 cigarettes smoked/day for one year. ${ }^{1}$ Quantification of pack years smoked is important in clinical care where degree of tobacco exposure is closely correlated to risk of disease. Smokers suffer an irreversible forced expiratory volume in one second $\left(\mathrm{FEV}_{1}\right)$ loss of 4.4-10.4 ml per pack year smoked. ${ }^{23}$ There is a strong dose-response relation between the number of pack years smoked and the risk, ${ }^{4}$ severity, ${ }^{5}$ and mortality ${ }^{6}$ of chronic obstructive pulmonary disease and the risk of lung cancer. ${ }^{7}$ Pack year smoking histories are important for quantification of tobacco exposure in research for direct study, to define patient groups or to determine confounding effects of smoking on outcomes from other exposures.

Although the number of ready made cigarettes smoked can easily be quantified in pack years, there is no well established method for measuring loose tobacco use. In this study we determined whether there was a need to quantify loose tobacco exposure and developed a simple method for converting loose tobacco use into pack years.

\section{PARTICIPANTS, METHODS, AND RESULTS}

Prevalence of previous or current loose tobacco use was investigated by a two day cross sectional survey of hospital in-patients $>16$ years old. Age, sex, in-patient speciality, smoking history, and lifetime loose tobacco use of participants were recorded. The relation between ready made cigarettes and loose tobacco was estimated by weight. The ability of physicians of different grades (table 1) to calculate pack years was assessed by questionnaire. Scenarios for ready made cigarettes $(n=5)$ and loose tobacco $(n=5)$ were given for conversion into total number of pack years smoked.

A total of 333 hospital in-patients were approached and $247(74 \%)$ completed the survey. Non-participants were confused $(\mathrm{n}=17)$, unwilling $(\mathrm{n}=14)$, or too unwell $(\mathrm{n}=55)$. Of the participants, $22.7 \%$ were current smokers, $41.3 \%$ were ex-smokers, and 36\% had never smoked; $41.3 \%$ of current/ex-smokers and $25.9 \%$ of all participants had smoked loose tobacco. Males $(40.5 \%)$ were more likely than females to be current/ex-smokers (males $71 \%$, females $58.3 \%$, $\mathrm{p}=0.029, \chi^{2}$ test) or have smoked loose tobacco (males $62.9 \%$, females 23.2\%, p $<0.0001$ ). Participants under medical or surgical consultants were equally likely to be current/ex-smokers $(p=0.34)$ or have smoked loose tobacco $(p=0.24)$. Ages were similar in those who had (mean (SD) 62.0 (18.6) years) or had not smoked loose tobacco (61.8 (20.4) years, $\mathrm{p}=0.45$, unpaired $t$ test).

The mean (SD) weight of tobacco per ready made cigarette was $0.73(0.029)(\mathrm{n}=20)$ and 20 cigarettes approximated a $12.5 \mathrm{~g}$ (1/2 ounce) sachet of loose tobacco. Loose tobacco users usually describe tobacco smoked in "ounces per week", which can be converted into pack years:

Table 1 Responses of medical and surgical pre-registration house officers (PRHO), medical senior house officers (SHO), respiratory specialist registrars (SpR), and general medicine consultants to history taking questionnaire and scenario assessment. Results are based on returned questionnaires

\begin{tabular}{|c|c|c|c|c|}
\hline & $\begin{array}{l}\text { Medical/ } \\
\text { surgical PRHO }\end{array}$ & $\begin{array}{l}\text { Medical } \\
\text { SHO }\end{array}$ & $\begin{array}{l}\text { Respiratory } \\
\text { SpR }\end{array}$ & $\begin{array}{l}\text { Medical } \\
\text { consultant }\end{array}$ \\
\hline Number surveyed & 23 & 11 & 18 & 17 \\
\hline Number of respondents (\%) & 18 (78.3) & $11(100)$ & $16(88.9)$ & $10(55.6)$ \\
\hline $\begin{array}{l}\text { Converts ready made cigarette use into } \\
\text { "pack years" in clinical practice (\% of } \\
\text { respondents) }\end{array}$ & $13(72.2)$ & $4(36.3)$ & $14(87.5)$ & $3(30)$ \\
\hline $\begin{array}{l}\text { Converts loose tobacco use into "pack } \\
\text { years" in clinical practice (\% of respondents) }\end{array}$ & $0(0)$ & $0(0)$ & $3(18.8)$ & $2(20)$ \\
\hline $\begin{array}{l}\text { Scenario score (maximum 5) for conversion } \\
\text { of ready made cigarettes into pack years } \\
\text { (mean (SD) of respondents) }\end{array}$ & $4.2(1.1)$ & $3.9(1.9)$ & $4.6(0.6)$ & $3.2(2.3)$ \\
\hline $\begin{array}{l}\text { Scenario score (maximum 5) for conversion } \\
\text { of loose tobacco use into pack years } \\
\text { (mean (SD) of respondents) }\end{array}$ & $0(0)$ & $0(0)$ & $0.2(0.4)$ & $0(0)$ \\
\hline
\end{tabular}


ounces per week $\times 2 / 7 \times$ number of years smoked $=$ pack years

Fifty five of 69 (79.7\%) physicians approached completed the questionnaire (table 1). Physicians were able to and commonly did convert ready made cigarettes into pack years (score $4.1 \pm 1.4 / 5)$. Physicians were unable to quantify loose tobacco use (score $0 \pm 0.2 / 5$ ).

\section{DISCUSSION}

We have shown that many smokers use loose tobacco, and that clinicians are unable to quantify loose tobacco use. We have therefore developed a simple formula to allow quantification of loose tobacco and ready made cigarette consumption in the same "units" for estimation of total smoking load. This formula has application both in clinical practice and research.

The formula has limitations as it does not allow for different smoking habits. Loose tobacco is more commonly smoked without a filter than ready made cigarettes, and smoking habits are determined by tar and nicotine content of the tobacco. ${ }^{89}$ Despite this we feel our formula is useful because of the strong dose-response relation between total tobacco consumption and ill health. ${ }^{2}$ Other variables such as inhalation and use of filters have not consistently been shown to influence clinical outcomes. ${ }^{710}$

\section{Authors' affiliations}

D M Wood, Pharmacology and Clinical Pharmacology, St George's Hospital Medical School, London, UK

M G Mould, S B Y Ong, St George's Hospital Medical School E H Baker, Physiological Medicine, St George's Hospital Medical School

Correspondence to: Dr Emma Baker, Physiological Medicine, St George's Hospital Medical School, Cranmer Terrace, London SW17 ORE, UK; ebaker@sghms.ac.uk

Received 13 September 2004

Accepted 23 November 2004

\section{What this paper adds}

There is no well established method for quantifying lifetime use of loose tobacco. We found that loose tobacco use was common in hospital in-patients, implying that measurement of this use was desirable. We therefore developed a simple weight based conversion of loose tobacco into "pack years" smoked which should be used in clinical practice and research: ounces per week $\times 2 / 7 \times$ number of years smoked $=$ pack years

\section{REFERENCES}

1 Prignot J. Quantification and chemical markers of tobacco-exposure. Eur J Respir Dis 1987:70:1-7.

2 Dockery DW, Speizer FE, Ferris BG, et al. Cumulative and reversible effects of lifetime smoking on simple tests of lung function in adults. Am Rev Respir Dis 1988; 137:286-92.

3 Prescott E, Bierg AM, Anderson PK, et al. Gender difference in smoking effects on lung function and risk of hospitalization for COPD: results from a Danish longitudinal population study. Eur Respir J 1997;10:822-7.

4 Jaen Diaz JI, de Castro Mesa C, Gontan Garcia-Salamanca MJ, et al. Prevalence of chronic obstructive pulmonary disease and risk factors in smokers and ex-smokers. Arch Bronconeumol 2003;39:554-8.

5 Kornmann O, Beeh KM, Beier J, et al. Global initiative for obstructive lung disease. Newly diagnosed chronic obstructive pulmonary disease. Clinical features and distribution of the novel stages of the global initiative for obstructive lung disease. Respiration 2003;70:67-75.

6 Kanner RE, Renzetti AD Jr, Stanish WM, et al. Predictors of survival in subjects with chronic airflow limitation. Am J Med 1983;74:249-55.

7 Agudo A, Ahrens W, Benhamou E, et al. Lung cancer and cigarette smoking in women: a multicenter case-control study in Europe. Int $J$ Cancer 2000;88:820-7.

8 Wald NJ, Idle M, Boreham J, et al. Inhaling habits among smokers of different types of cigarettes. Thorax 1980;35:925-8.

9 Wald NJ, Boreham J, Bailey A. Relative intakes of tar, nicotine, and carbon monoxide from cigarettes of different yields. Thorax 1984;39:361-4.

10 Beck GJ, Doyle CA, Schachter EN. Smoking and lung function. Am Rev Respir Dis 1981;123:149-55.

\section{The Lighter Side}

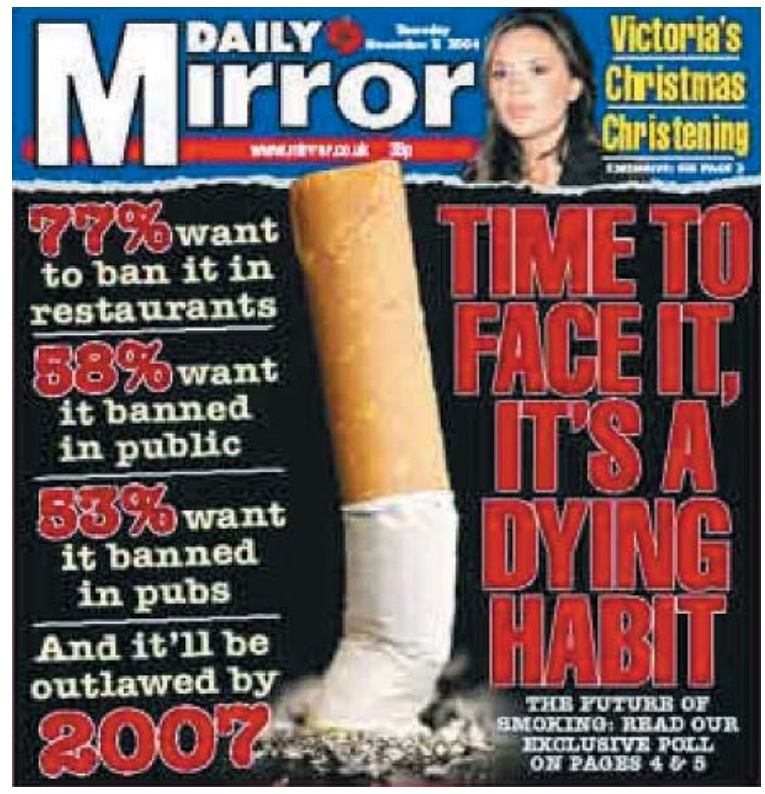

A November 2004 poll in London's Daily Mirror shows an encouraging shift in public opinion on public place smoking bans. 